Received: 19 March 2018

Accepted: 21 August 2018

Published online: 06 September 2018

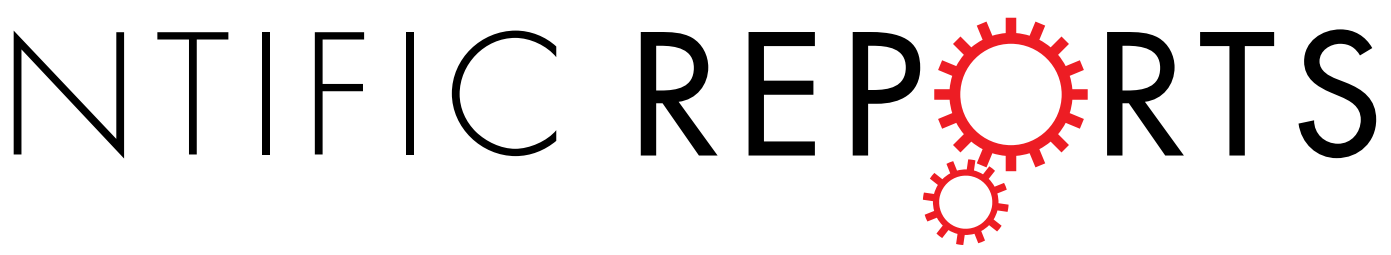

\section{OPEN \\ Time-advanced occurrence of moderate-size earthquakes in a stable intraplate region after a megathrust earthquake and their seismic properties}

\begin{abstract}
Tae-Kyung Hong $\mathbb{D}^{1}$, Junhyung Lee $\mathbb{D}^{1}$, Seongjun Park ${ }^{1} \&$ Woohan Kim ${ }^{2}$
The distance-dependent coseismic and postseismic displacements produced by the $2011 M_{w} 9.0$ Tohoku-Oki megathrust earthquake caused medium weakening and stress perturbation in the crust around the Korean Peninsula, increasing the seismicity with successive $M_{L} 5$-level earthquakes at the outskirts of high seismicity regions. The average $M_{L} 5$-level occurrence rate prior to the megathrust earthquake was $0.15 \mathrm{yr}^{-1}\left(0.05-0.35 \mathrm{yr}^{-1}\right.$ at a $95 \%$ confidence level), and the rate has increased to $0.71 \mathrm{yr}^{-1}\left(0.23-1.67 \mathrm{yr}^{-1}\right.$ at a $95 \%$ confidence level) since the megathrust earthquake. The $2016 \mathrm{M}_{L} 5$ level midcrustal earthquakes additionally changed the stress field in adjacent regions, inducing the 15 November $2017 M_{L} 5.4$ earthquake. The successive 2016 and 2017 moderate-size earthquakes built complex stress fields in the southeastern Korean Peninsula, increasing the seismic hazard risks in the regions of long-term stress accumulation. The increased seismic risks may continue until the medium properties and stress field are recovered.
\end{abstract}

The Korean Peninsula is located in a stable intraplate region of the eastern Eurasian plate. The continental crust lies in the peninsula and the Yellow Sea. A transitional crust between continental and oceanic crusts has developed in the East Sea (Sea of Japan $)^{1-5}$. The region around the peninsula is under the influence of a compressional stress field with an ENE-directional compression and SSE-directional tension ${ }^{6,7}$ (Fig. 1). The instrumentally recorded earthquakes since 1978 indicated mild and diffused seismicity (Fig. 1).

However, the historical literature indicates large seismic damage on the Korean Peninsula. The largest seismic intensity reached IX on the modified Mercalli intensity (MMI) scale ${ }^{8}$. The historical seismicity displays high similarity with the instrumentally recorded seismicity over most regions in the Korean Peninsula, except the central peninsula around the Seoul metropolitan area ${ }^{8,9}$. The historical earthquake records present high seismicity with large earthquakes in the central peninsula.

The $2011 M_{W} 9.0$ Tohoku-Oki megathrust earthquake occurred $\sim 1200 \mathrm{~km}$ from the Korean Peninsula. The megathrust earthquake incorporated large lithospheric displacements up to regional distances ${ }^{10-12}$. The 2011 Tohoku-Oki megathrust earthquake produced coseismic displacements of $\sim 4 \mathrm{~cm}$ around the east coast and $\sim 2 \mathrm{~cm}$ around the west coast of the Korean Peninsula (Fig. 1) ${ }^{11,13,14}$. Comparable strengths of postseismic displacements followed the coseismic displacements for more than 3 years ${ }^{12,15}$.

The distance-dependent displacements produced tension stress over the Korea Peninsula ${ }^{11}$ (Fig. 1), and the discriminative crustal extension decreased the seismic velocity in the crust ${ }^{12,16-19}$. The seismicity increased abruptly after the megathrust earthquake, and unusual episodic earthquake swarms were observed for 60 days after 29 April 2013 and 120 days after 2 June 2013 at two regions in the Yellow Sea (Fig. 1) ${ }^{11}$. The seismicity increase may have been caused by the decreasing yield strength of the medium due to instantaneous activation of the tension field by crustal extension ${ }^{11}$. It was suggested that a small change in stress field may induce significant

${ }^{1}$ Yonsei University, Department of Earth System Sciences, 50 Yonsei-ro, Seodaemun-gu Seoul, 120-749, South Korea. ${ }^{2}$ Gyeongsang National University, Department of Earth and Environmental Sciences and RINS, Jinju, Gyeongsangnam-do, 660-701, South Korea. Correspondence and requests for materials should be addressed to T.-K.H. (email: tkhong@yonsei.ac.kr) 
a

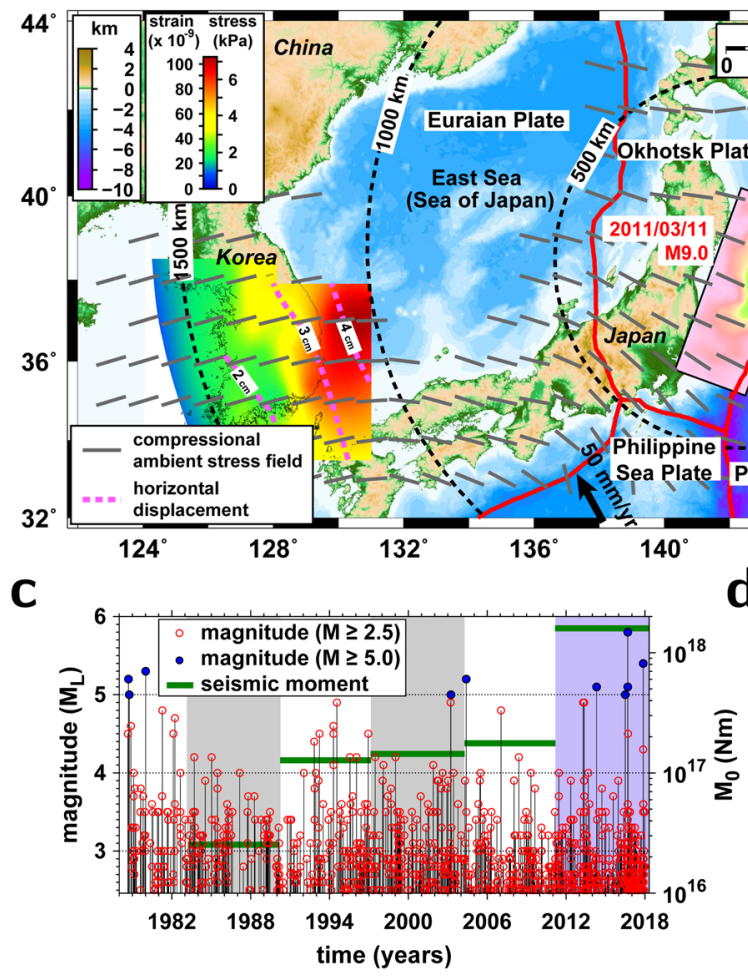

d b

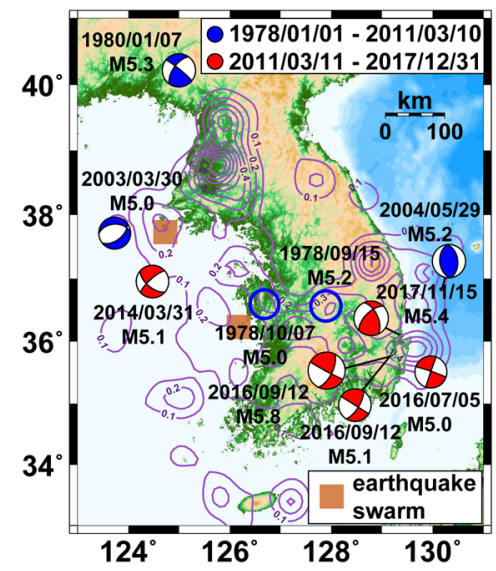

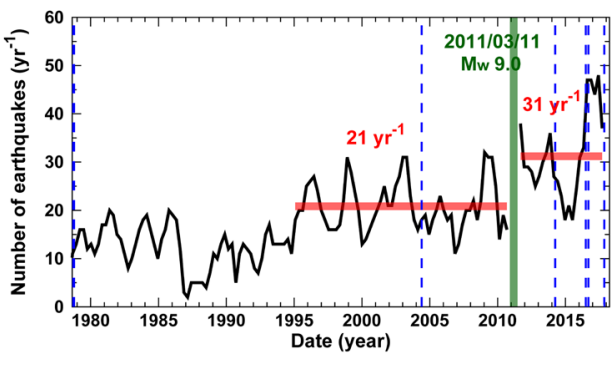

Figure 1. Moderate-size earthquake induction on the Korean Peninsula. (a) Map around the Korean Peninsula with a slip model of the $2011 M_{W} 9.0$ Tohoku-Oki megathrust earthquake. The primary compression field is presented with solid bars ${ }^{6}$. The tension field and coseismic displacements incurred by the megathrust earthquake over the Korean Peninsula are presented ${ }^{11}$. The coseismic slip during the megathrust earthquake is presented on the map ${ }^{10}$. (b) Earthquakes with magnitudes greater than or equal to $M_{L} 5.0$ since 1978. The seismicity densities of instrumentally recorded earthquakes since 1978 are presented with contours ${ }^{35}$. The locations of earthquake swarms since the 2011 megathrust earthquake are marked on the map. (c) Earthquake occurrence since 1978 in the Korean Peninsula. Events with magnitudes greater than or equal to 5.0 are indicated. The total seismic moments emitted by the earthquakes every seven years are shown. The emitted seismic moments increased after the megathrust earthquake. (d) Temporal variation in yearly numbers of earthquakes with magnitudes greater than or equal to 2.5 from a declustered catalog. The average number of earthquakes was $21 \mathrm{yr}^{-1}$ before the 2011 Tohoku-Oki megathrust earthquake and $31 \mathrm{yr}^{-1}$ after the earthquake. The dates of earthquakes with magnitudes of $M \geq 5.0$ are marked with broken lines. The seismicity increased abruptly after the megathrust earthquake. The figure was created using GMT 4.5.14 (https://www.soest.hawaii. edu/gmt/) and Adobe Illustrator CS6 (https://www.adobe.com/kr/products/illustrator.html).

seismicity changes ${ }^{20}$. The earthquakes occurred in both high seismicity regions and low seismicity regions, suggesting that the earthquakes were fostered in the low seismicity region ${ }^{11,21}$.

The stress field inferred from the focal mechanism solutions of earthquakes after the 2011 Tohoku-Oki megathrust earthquake is close to the ambient stress field inferred from the focal mechanism solutions of earthquakes before the 2011 Tohoku-Oki megathrust earthquake. The compression-axis directions of the 12 September 2016 $M_{L} 5.8$ earthquake and its aftershocks were $\mathrm{N} 70^{\circ} \mathrm{E}$ to $\mathrm{N}^{\circ} 7^{\circ} \mathrm{E}^{22}$. The maximum compression-axis directions of the ambient stress field before the megathrust earthquake were $\sim \mathrm{N} 77^{\circ} \mathrm{E}\left( \pm 1.2^{\circ} \text { at a } 95 \% \text { confidence level }\right)^{6}$. Small changes in the stress field and medium properties produce earthquakes with new fault planes whose orientations conform to the stress field ${ }^{11}$. Earthquakes with different faulting types occurred after the megathrust earthquake $^{11}$, possibly due to abrupt changes in differential stresses that develop new fault planes with different faulting behavior ${ }^{23,24}$.

Ten $M_{L} 5$-level earthquakes have occurred on the Korean Peninsula since 1978, when national seismic monitoring was commenced (Fig. 1). The $M_{L}$ 5-level earthquakes were generally scattered around the suburbs of high seismicity regions (Fig. 1). The number of $M_{L}$ 5-level earthquakes has increased since the 2011 Tohoku-Oki megathrust earthquake: one-half of the moderate-size earthquakes (5 events) occurred since the 2011 Tohoku-Oki megathrust earthquake. We investigate the properties of the successive $M_{L} 5$-level earthquakes and their induction mechanisms on the Korean Peninsula. 


\section{Results}

Seismicity change. The seismic velocities in the crust of the Korean Peninsula decreased by 3\% instantly after the 2011 Tohoku-Oki megathrust earthquake ${ }^{12}$. Seismic velocities are recovered with time ${ }^{12}$. We examine the seismicity changes by declustering the seismicity, which excludes the aftershocks from the earthquake catalog (Fig. 1) (see supplementary materials). The earthquake catalog since 1978 is complete for seismicity with magnitudes greater than or equal to $M_{L} 2.5^{9,11}$ (see supplementary materials). The declustered seismicity of earthquakes with $M_{L} \geq 2.5$ presents seismicity rates of $21 \mathrm{yr}^{-1}\left(18.72-23.25 \mathrm{yr}^{-1}\right.$ at a $95 \%$ confidence level) prior to the megathrust earthquake and $31 \mathrm{yr}^{-1}\left(27.13-35.53^{-1}\right.$ at a $95 \%$ confidence level) since the megathrust earthquake (Fig. 1).

The increase in seismicity rate was caused an increase in seismic energy emission. The seismic moments emitted from the earthquakes on the Korean Peninsula for 82 months since the 2011 Tohoku-Oki megathrust earthquake were more than 10 times larger than those before the megathrust earthquake for the same time duration (Fig. 1).

The seismicity before the megathrust earthquake may be a consequence of tectonic loading in the crust of the Korean Peninsula. The average occurrence rate of the ten $M_{L}$ 5-level earthquakes for the 40 years of 1978-2018 is $0.25 \mathrm{yr}^{-1}\left(0.12-0.46 \mathrm{yr}^{-1}\right.$ at a $95 \%$ confidence level). The occurrence rate prior to the megathrust earthquake, $0.15 \mathrm{yr}^{-1}\left(0.05-0.35 \mathrm{yr}^{-1}\right.$ at a $95 \%$ confidence level $)$ changed to $0.71 \mathrm{yr}^{-1}\left(0.23-1.67 \mathrm{yr}^{-1}\right.$ at a $95 \%$ confidence level) after the megathrust earthquake. The probabilities of having five $M_{L} 5$-level earthquakes in the 7 years since the megathrust earthquake are less than $3 \%$ and $1 \%$ for occurrence rates of $0.25 \mathrm{yr}^{-1}$ and $0.15 \mathrm{yr}^{-1}$ in terms of Poissonian earthquake occurrence ${ }^{25,26}$ (see supplementary materials). This observation suggests that the recent $M_{L}$ 5-level earthquakes since the 2011 megathrust earthquake may be time-advanced events that might otherwise have occurred at later times ${ }^{27}$.

The first $M_{L}$ 5-level earthquake $\left(M_{L} 5.1\right)$ since the megathrust earthquake occurred on 31 March 2014 in the Yellow Sea. An $M_{L} 5.0$ earthquake occurred in a region off the southeastern coast on 5 June 2016. Midcrustal $M_{L} 5.1$ and 5.8 earthquakes occurred within a time interval of $48 \mathrm{~min}$ on the southeastern Korean Peninsula on 12 September $2016^{22}$. The $M_{L} 5.8$ earthquake was the largest event in the instrumental seismic monitoring history since 1978. The event occurred in a midcrustal blind fault ${ }^{22}$, and it released the stress of the fault to adjacent regions, producing aftershocks. The aftershocks occurred dominantly for more than 1 year in regions with positive Coulomb stress changes.

The 15 November $2017 M_{L} 5.4$ earthquake occurred in a region of positive Coulomb stress changes by the 2016 $M_{L}$ 5-level earthquakes ${ }^{22}$. The fault planes of the moderate-size events in 2016 and 2017 were not found on the surface. The 2016 and 2017 moderate-size earthquakes both produced strong seismic waves, presenting similar spatial distributions of ground motion over the Korean Peninsula (Fig. 1). The peak seismic intensities of the events reached VIII on the modified Mercalli intensity (MMI) scale. The $2016 M_{L} 5.8$ earthquake yielded relatively stronger energy at frequencies of $1-4 \mathrm{~Hz}$, while the $2017 M_{L} 5.4$ earthquake yielded large energy at frequencies of $0.15-0.5 \mathrm{~Hz}$ (Fig. 1).

Time-advanced earthquakes. We investigate the properties of time-advanced earthquakes in a stable intraplate region from the three inland $M_{L}$ 5-level earthquakes in 2016 and 2017. The two consecutive $M_{L} 5$-level $\left(M_{L} 5.1,5.8\right)$ midcrustal earthquakes on 12 September 2016 perturbed the local stress field significantly ${ }^{22}$. Earthquakes started to occur in the regions of positive Coulomb stress changes induced by the 2016 moderate-size earthquakes (see supplementary materials).

The $2017 M_{L} 5.4$ earthquake region was seismically quiescent before the 2011 Tohoku-Oki megathrust earthquake (see supplementary materials). Note that no events with magnitudes greater than or equal to 2.0 were reported in the epicenter region with a radius of $10 \mathrm{~km}$ before the $2016 M_{L} 5$-level earthquakes. Four earthquakes with magnitudes greater than or equal to $2.0\left(M_{L} 2.0,2.2,2.3,3.1\right)$ occurred around the epicentral region with a radius of $3 \mathrm{~km}$ since the $2016 M_{L} 5$-level earthquakes.

The seismic moment of the $2017 M_{L} 5.4$ earthquake was $1.85 \times 10^{17} \mathrm{Nm}$, and the corresponding moment magnitude was $M_{w} 5.5$ (see supplementary materials). The strike of the fault was $\mathrm{N} 45^{\circ} \mathrm{E}$, and the dip was $61^{\circ}$ to the west. The fault for the $2016 M_{L} 5.8$ earthquake presented a strike of $\mathrm{N} 27^{\circ} \mathrm{E}$ and dip of $65^{\circ}$ to the east ${ }^{22}$. The refined focal depth of the $2017 M_{L} 5.4$ earthquake was $6.2 \mathrm{~km}$. The earthquake showed a combined motion sense of reverse and strike-slip faulting (Fig. 2). The seismic energy was composed of a double-couple component (67\%) and compensated linear vector dipole (CLVD) component (33\%). This observation suggests a complex fault geometry and rupture.

The aftershock occurrence rate of the $2017 M_{L} 5.4$ earthquake was smaller than that of the $2016 M_{L} 5.8$ earthquake. The aftershocks of the $2016 M_{L} 5.8$ earthquake lasted for more than one year. The number of aftershocks of the $2017 M_{L} 5.4$ earthquake decreased rapidly with time (Fig. 2). However, the magnitudes of the aftershocks decreased with time at similar decay rates. The aftershocks of the $2017 M_{L} 5.4$ earthquake were located at depths between 4 and $11 \mathrm{~km}$, while those of the $2016 M_{L} 5.8$ earthquake were distributed at depths between 11 and $16 \mathrm{~km}^{22}$ (Fig. 2). The focal depths of the mainshocks and aftershocks of the $2016 M_{L} 5.8$ earthquake and the 2017 $M_{L} 5.4$ earthquake were within the typical seismicity depths $(4-20 \mathrm{~km})$ on the Korean Peninsula ${ }^{28}$.

The seismic energy from the $2017 M_{L} 5.4$ earthquake was rich in low frequencies around $\sim 0.5 \mathrm{~Hz}$ compared to that from the $2016 M_{L} 5.8$ earthquake (Fig. 2) 22 . The levels of displacement spectra of the $2016 M_{L} 5.8$ earthquake and the $2017 M_{L} 5.4$ earthquake at a common station at comparable distances were similar, despite an apparent magnitude difference in the local magnitude scale. The spatial distribution of the peak ground accelerations (PGAs) of the $2017 M_{L} 5.4$ earthquake was similar to that of the $2016 M_{L} 5.8$ earthquake (Fig. 2). The PGA decays gradually with distance on the Korean Peninsula ${ }^{29}$. The characteristic slow distance-dependent decay of PGAs suggests a high potential for seismic damage over wide regions when a large event occurs in the stable intraplate region. 
a

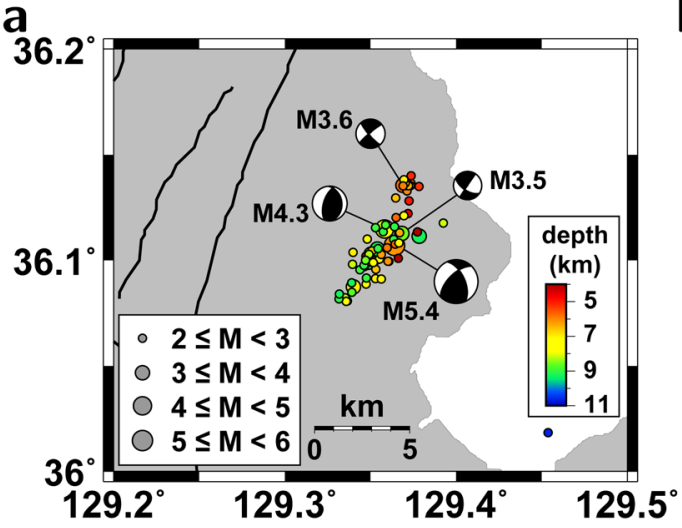

b

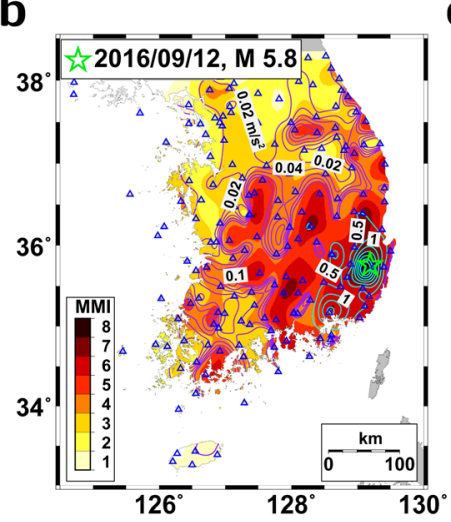

C

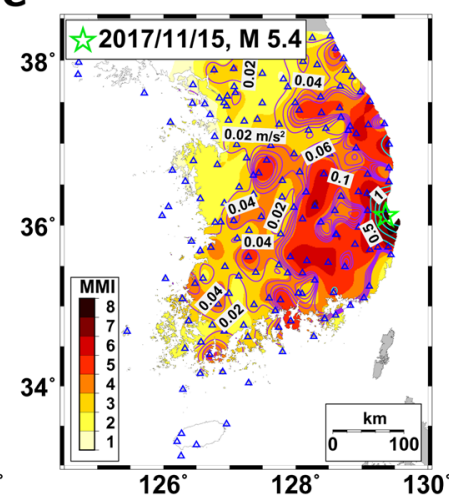

d

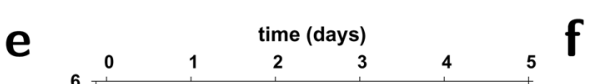
f

g
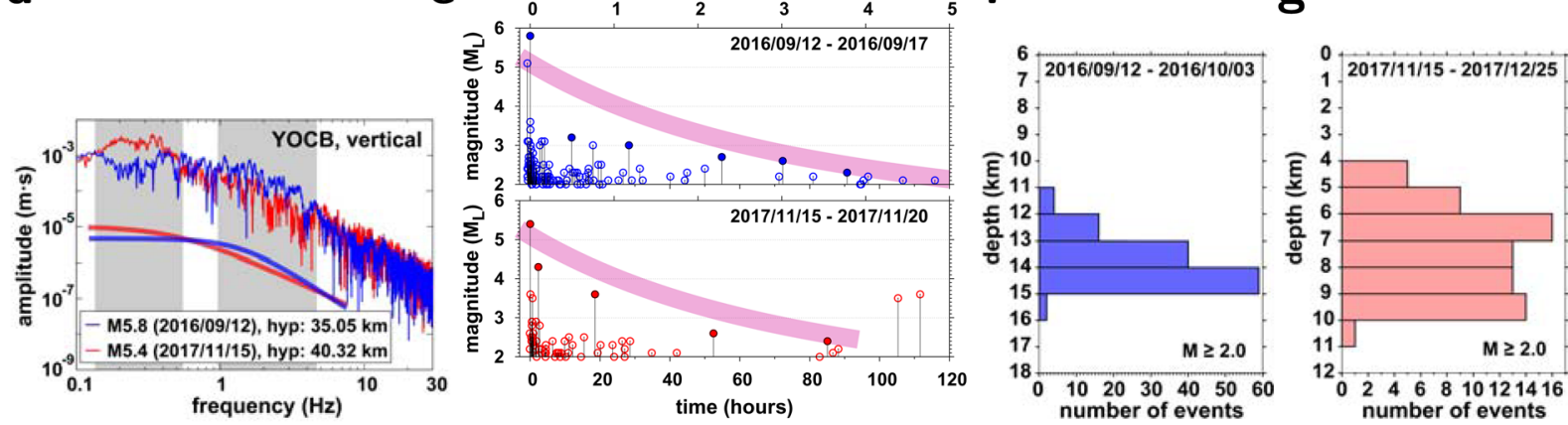

Figure 2. Seismic properties of two moderate-size earthquakes. (a) Spatial distribution of the 15 November $2017 M_{L} 5.4$ earthquake and its aftershocks. Focal mechanism solutions of major earthquakes with the focal depths indicated. The events display different types of faulting. Peak ground accelerations in $\mathrm{m} / \mathrm{s}$ and seismic intensities in the modified Mercalli intensity (MMI) scale of (b) the 15 November $2017 M_{L} 5.4$ earthquake and (c) the 12 September $2016 M_{L} 5.8$ earthquake. The seismic stations are marked with triangles. The spatial distributions of the seismic intensities of the events are comparable. (d) Comparison of the vertical displacement spectra of the $2017 M_{L} 5.4$ earthquake and the $2016 M_{L} 5.8$ at comparable distances at a common station (YOCB). The displacement spectra of the $2017 M_{L} 5.4$ earthquake are rich in the low frequencies of $0.15-0.5 \mathrm{~Hz}$. The $2016 M_{L} 5.8$ earthquake displays relatively strong energy in the high frequencies of $1-4 \mathrm{~Hz}$. (e) Aftershock occurrence with time after the $2016 M_{L} 5.8$ earthquake and the $2017 M_{L} 5.4$ earthquake. Comparison of focal depths of aftershocks between (f) the $2016 M_{L} 5.8$ earthquake and (g) the $2017 M_{L} 5.4$ earthquake. The aftershocks of the $2017 M_{L} 5.4$ earthquake occur at shallower depths than those of the 2016 $M_{L} 5.8$ earthquake. The figure was created using GMT 4.5.14 (https://www.soest.hawaii.edu/gmt/) and Adobe Illustrator CS6 (https://www.adobe.com/kr/products/illustrator.html).

The ground motions were particularly strong in the Quaternary sedimentary basin (Gyeongsang Basin) of the southeastern Korean Peninsula. The epicenter region of the $2017 M_{L} 5.4$ earthquake is covered by a Tertiary sedimentary layer that causes seismic amplification. Significant liquefaction around the epicentral region was reported, which was not common in the earthquakes of the Korean Peninsula. The property damage from the $2017 M_{L} 5.4$ earthquake was much higher than that from the $2016 M_{L} 5.8$ earthquake. This difference may be partly due to the low-frequency-rich ground motions and surface sedimentary layer of the epicentral region in the 2017 $M_{L} 5.4$ earthquake.

Blind faults incurring time-advanced earthquakes. The faults responsible for the three $M_{L} 5$-level earthquakes in 2016 and 2017 were not recognized before their occurrence. The $2016 M_{L} 5.1$ and 5.8 earthquakes occurred in a strike-slip fault at depths between 11 and $16 \mathrm{~km}^{22}$. The dip of the fault was $\sim 65^{\circ}$ to the east. Additionally, the $2017 M_{L} 5.4$ earthquake occurred in a blind crustal fault (Fig. 3). The aftershocks of the 2017 $M_{L} 5.4$ earthquake were distributed in a volume of $8 \times 3 \times 6 \mathrm{~km}^{3}$. The aftershock distribution and fault-plane solutions illuminate the geometry of the fault, which may be divided by three segments (Fig. 3 ).

Each fault segment developed at a different depth (Fig. 3). The focal depths of the earthquakes in the northeastern segment were shallow $(4.5-7.2 \mathrm{~km})$. On the other hand, most earthquakes in the southwestern segment were distributed at greater depths $(\geq 6 \mathrm{~km})$. The focal mechanism solutions of the earthquakes in the southwestern and northeastern segments indicate right-lateral strike-slip faults. By contrast, the focal mechanism solution of the $M_{L} 4.3$ earthquake in the central segment suggests a reverse faulting with a strike of $\mathrm{N} 18^{\circ} \mathrm{E}$ and a dip of $62^{\circ}$. The seismic moment was $3.66 \times 10^{22} \mathrm{Nm}$, and the corresponding moment magnitude was $M_{w} 4.3$.

The mainshock occurred at the boundary between the southwestern and central segments. The early sequence of aftershocks was located mainly in the southwestern segment, accompanying some aftershocks in 
a
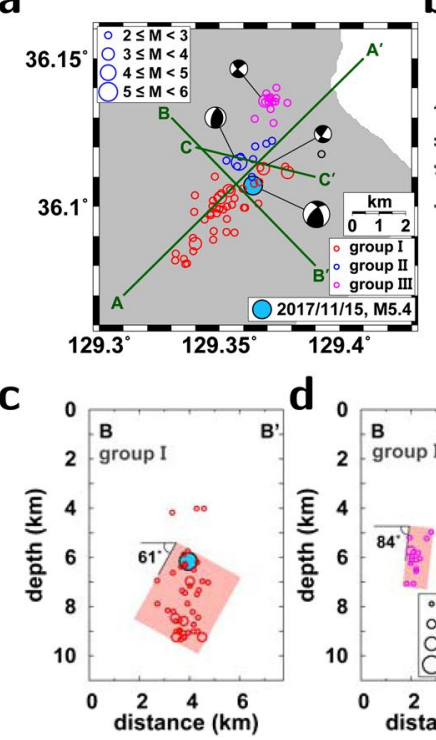

d 0 b
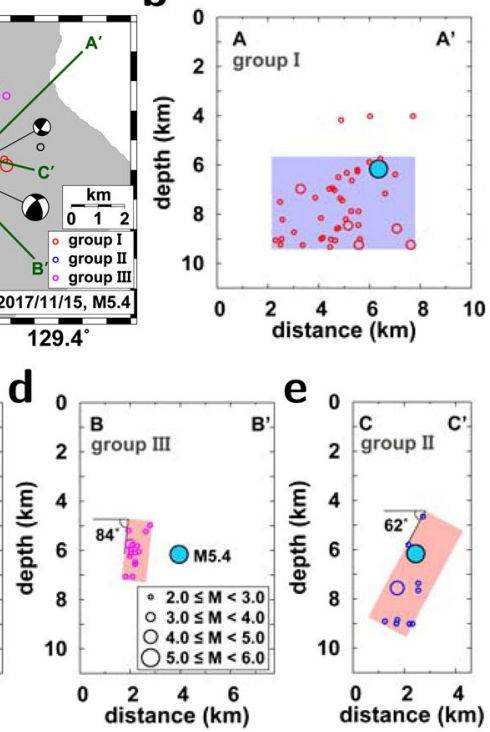

e 0

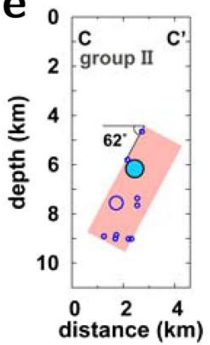

f

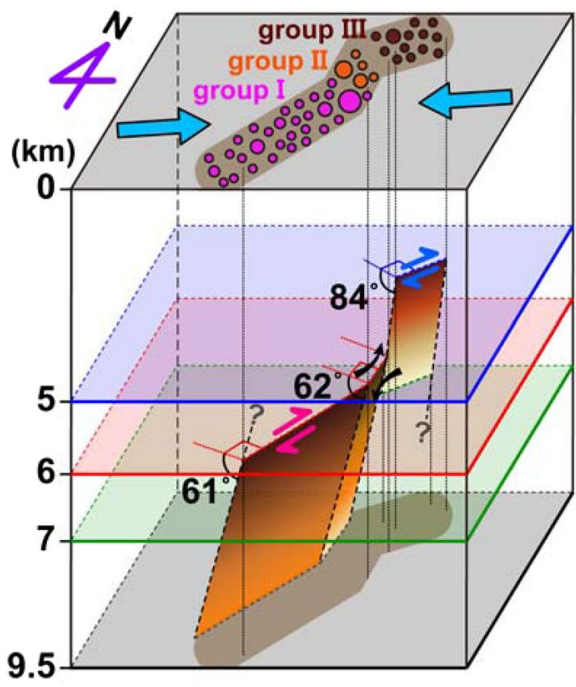

Figure 3. The $2017 M_{L} 5.4$ earthquake and its aftershocks. (a) Map and cross sections of the mainshock and aftershocks. The earthquakes are divided into three groups. Vertical distribution of events for (b) group I along cross section AA', (c) group I along cross section BB', (d) group III along cross section BB', and (e) group II along cross section CC. The vertical distribution of aftershocks agrees with the focal mechanism solutions of major earthquakes. (f) Fault model and interaction between fault segments. The fault is divided into three fault segments at different depths. The figure was created using GMT 4.5.14 (https://www.soest.hawaii.edu/gmt/) and Adobe Illustrator CS6 (https://www.adobe.com/kr/products/illustrator.html).

the northeastern segment. Most of the aftershocks in the northeastern segment started to occur 2 hours after the mainshock (see supplementary materials). The later sequence of aftershocks was clustered around the central segment, which is located less than $2 \mathrm{~km}$ to the north of the mainshock. The earthquake migration suggests time-dependent faulting. Furthermore, the compression-axis directions of the $2017 M_{L} 5.4$ earthquake and its aftershocks with magnitudes of $M_{L} \geq 3.6$ for three months were determined to be similar ( $80^{\circ} \mathrm{W}$ to $\left.\mathrm{N} 88^{\circ} \mathrm{W}\right)$. This observation suggests that the mainshock and aftershocks occurred under a constant stress environment.

The lateral distributions of aftershocks in the southwestern and northeastern segments are consistent with the strike of the mainshock. The fault plane in the southwestern segment dips to the NW at an angle of $61^{\circ}$ from the surface. The fault plane of the northeastern segment developed at depths between 5.0 and $7.2 \mathrm{~km}$. The dipping angle was $84^{\circ}$. The southwestern segment is connected to the northeastern segment by the central segment. The central segment plays the role of conjunction between the southwestern and northeastern segments. The reverse-faulting in the central segment may have been caused by lateral-stepwise motions of the northeastern and southwestern segments at different depths, inducing a vertical dislocation in the central segment (Fig. 3).

Induction mechanism of time-advanced earthquakes. The crust of the Korean Peninsula was stretched by the differential coseismic and postseismic displacements due to the 2011 Tohoku-Oki megathrust earthquake, reducing the yield strengths in the crust $^{12}$.

The $2016 M_{L} 5.1$ and $M_{L} 5.8$ earthquakes produced Coulomb stress changes of -4.9 to 2.5 bar for optimally oriented strike-slip faults at a depth of $10 \mathrm{~km}$ (Fig. 4). The induced Coulomb stress change for optimally oriented strike-slip faults at the location of the $2017 M_{L} 5.4$ earthquake was $0.5 \times 10^{-2}$ bar. The optimal orientation of right-lateral strike-slip faults was $\mathrm{N} 41^{\circ} \mathrm{E}$, which is close to the fault strike of the $2017 M_{L} 5.4$ event $\left(\mathrm{N} 45^{\circ} \mathrm{E}\right)$ (see supplementary materials). We found that the induced Coulomb stress change for the $2016 M_{L} 5.1$ and $M_{L} 5.8$ earthquakes for the illuminated fault geometry of the $2017 M_{L} 5.4$ earthquake was $0.2 \times 10^{-2}$ bar at the hypocenter of the $2017 M_{L} 5.4$ earthquake. The increased stress at the $2017 M_{L} 5.4$ earthquake region was sufficiently larger than the critical stress change level $\left(\sim 1 \times 10^{-4}\right.$ bar $)$ required to trigger earthquakes ${ }^{30}$.

No earthquakes with magnitudes greater than $M_{L} 2.0$ occurred in the region around the $2017 M_{L} 5.4$ earthquake before the occurrence of the $2016 M_{L} 5.1$ and $M_{L} 5.8$ earthquakes (see supplementary materials). The 2016 $M_{L} 5.1$ and $M_{L} 5.8$ earthquakes appeared to be the primary source of stress changes in the region of the $2017 M_{L} 5.4$ earthquake. The $2017 M_{L} 5.4$ earthquake occurred in a region of increased stress caused by the $2016 M_{L} 5.1$ and $M_{L} 5.8$ earthquakes.

The $2017 M_{L} 5.4$ earthquake caused additional stress changes, building a complex stress field around the southeastern Korean Peninsula (Fig. 4). The successive earthquakes in 2016-2017 perturbed the local stress field. The static stress in the interevent region between the $2016 M_{L} 5.8$ earthquake and the $2017 M_{L} 5.4$ earthquake was increased several fold by those earthquakes. Additionally, the 2016 and $2017 M_{L} 5$-level earthquakes produced positive Coulomb stress changes at the offshore region in the direction NE of the $2017 M_{L} 5.4$ earthquake. 

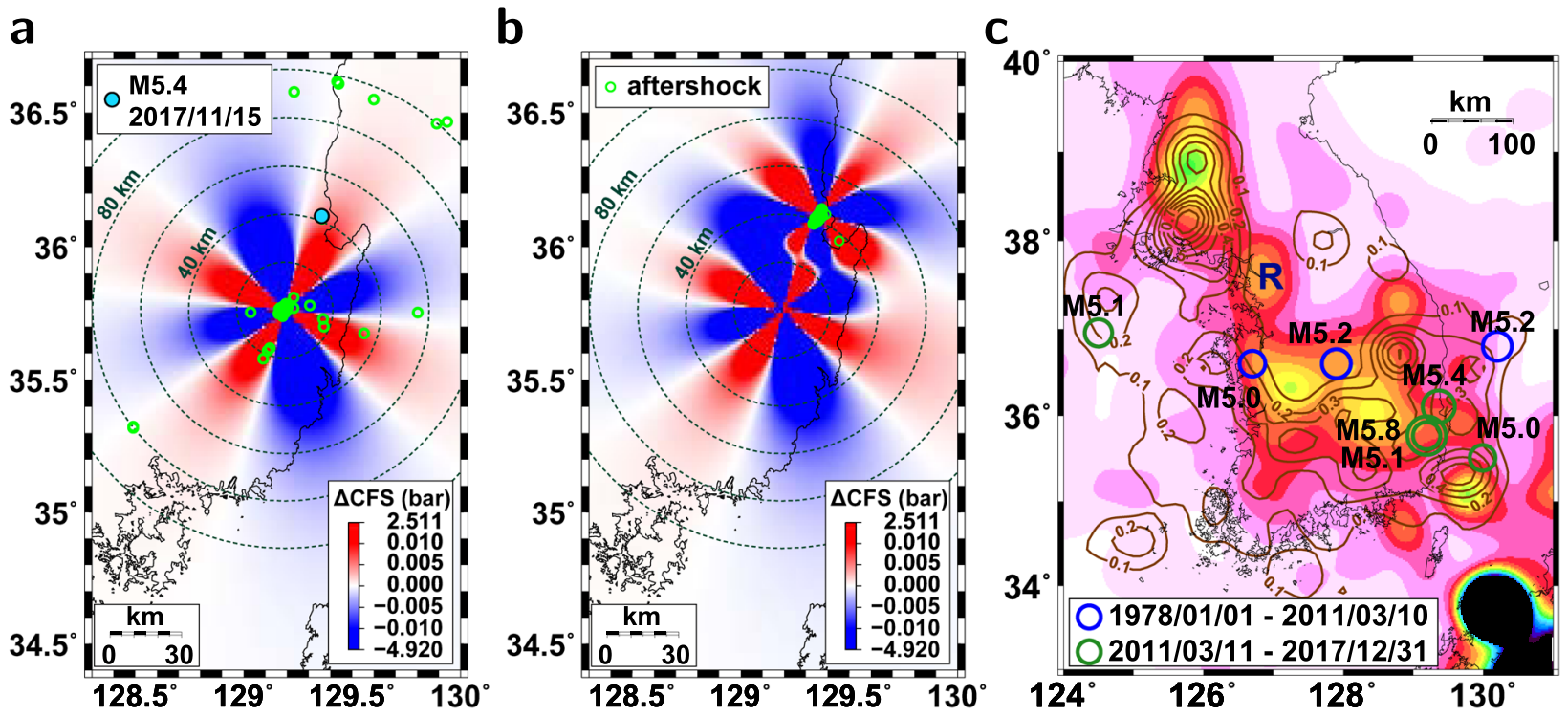

Figure 4. Coulomb stress changes and seismic hazard risks. (a) Coulomb stress changes at a depth of $10 \mathrm{~km}$ due to the $2016 M_{L} 5.8$ earthquake, and (b) those additionally affected by the $2017 M_{L} 5.4$ earthquake. The aftershocks of the $2017 M_{L} 5.4$ earthquake are presented (circles). The $2017 M_{L} 5.4$ earthquake occurred in a region of positive Coulomb stress change. The moderate-size earthquakes perturbed the local stress field. (c) Seismicity densities combined with instrumentally recorded earthquakes in 1978-2011 and historical earthquakes in 1392-1904 ${ }^{28}$. The instrumental seismicity densities (contours) are presented for comparison ${ }^{9}$. The epicenters of major earthquakes since 1978 are marked. The earthquakes are not observed around the Seoul metropolitan area (region R). The figure was created using GMT 4.5.14 (https://www.soest.hawaii.edu/gmt/) and Adobe Illustrator CS6 (https://www.adobe.com/kr/products/illustrator.html).

\section{Discussion and Conclusions}

Seismicity varies with stress ${ }^{31,32}$. Tectonic loading may be the primary source of the stress that has accumulated in the crust. The long-term tectonic-loading stress over the Korean Peninsula may be homogeneous. The 2011 $M_{W} 9.0$ Tohoku-Oki megathrust earthquake caused high perturbation in the medium and stress field. The induced stress change may play a crucial role in increasing the seismic hazard potential. A stress change may trigger earthquakes in regions of long-lived stress concentration ${ }^{33,34}$. The recent successive $M_{L} 5$-level earthquakes may be time-advanced events that are a consequence of medium weakening and stress perturbation due to the 2011 $M_{W} 9.0$ Tohoku-Oki megathrust earthquake and precedent adjacent events.

The recent inland $M_{L} 5$-level earthquakes occurred in crustal blind faults that were not identified before the events. Historically, large earthquakes have been recorded on the Korean Peninsula ${ }^{8,9,35}$. The recent increased seismicity with moderate-size earthquakes suggests high probability of hazardous-earthquake occurrence on the Korean Peninsula.

The spatial distribution of previous events may allow us to constrain the potential locations of future earthquakes. The seismicity density functions of instrumentally recorded and historical earthquakes may provide information on the stress released by precedent earthquakes (Figs 1 and 4). It is intriguing to note that the $M_{L}$ 5-level earthquakes occurred in low seismicity regions (Fig. 1). The recent moderate-size earthquakes might occur around high prestressed regions with long-term cumulation of tectonic loading ${ }^{36}$. Faults in near-critical conditions might respond preferentially to additional stress changes induced by the 2011 Tohoku-Oki megathrust earthquake ${ }^{32}$. A major event releases the cumulated stress of the fault, triggering another event in adjacent regions.

The medium properties were recovered gradually with time, restoring the stress field. Several regions of high seismicity densities with low recent seismic activities exist (Fig. 4). The increased seismicity may continue until the medium properties and stress field are recovered. A combined interpretation of the instrumentally recorded and historical seismicity may suggest potential locations of devastating events that occurred historically (Fig. 4).

\section{Methods}

The observed seismicity can be expressed as a sum of background seismicity and triggered seismicity ${ }^{37}$ :

$$
\lambda(x, t)=\lambda_{0}(x)+\sum_{t_{i}<t} \lambda_{i}(x, t)
$$

where $\lambda(x, t)$ is the observed seismicity rate density at time $t$ at location $x, \lambda_{0}(x)$ is the background intensity function, and $\lambda_{i}(x, t)$ is the contribution of earthquake $i$ that occurred in time $t_{i}$ at location $x_{i}$. We decluster the earthquake catalog based on a nonparametric method that is useful for regions with low seismicity rates. The functions $\lambda_{i}(x, t)$ and $\lambda_{0}(x)$ are determined by an iterative process that assesses the numbers of event pairs in discrete bins of magnitudes, interevent times and distances ${ }^{37-39}$ (see supplementary materials). 
We perform a long-period waveform inversion of earthquakes to determine the focal mechanism solutions ${ }^{11,40}$ based on a global-averaged one-dimensional (1-D) velocity model ${ }^{41}$. We determine a set of hypocentral parameters that generate the best-fit synthetic waveforms ${ }^{42}$. The focal mechanism solutions of the earthquakes are determined based on 5 seismic records of $0.05-0.1 \mathrm{~Hz}$ in regional distance (Fig. 2).

The hypocentral parameters of the earthquakes are refined using VELHYPO based on the $P$ and $S$ arrival times (see supplementary materials) ${ }^{43,44}$. This method is effective for the determination of hypocentral parameters of earthquakes in media with poorly known velocity structures (see supplementary materials). We implement a 1 -D velocity model as the initial model ${ }^{45}$. We analyze 14 to 34 three-component waveforms of each earthquake for the hypocentral-parameter inversion. The average $P$ and $S$ travel time residuals are $6.1 \times 10^{-6} \mathrm{~s}$ and $4.9 \times 10^{-3} \mathrm{~s}$, and their standard deviations are $0.0489 \mathrm{~s}$ and $0.1948 \mathrm{~s}$, respectively (see supplementary materials). The horizontal and vertical location errors at the $95 \%$ confidence level are $9.7 \mathrm{~m}$ and $24.3 \mathrm{~m}$. The origin time and hypocenter errors are sufficiently small.

The induced Coulomb stress change, $\triangle \mathrm{CFS}$ can be represented by ${ }^{46,47}$

$$
\Delta \mathrm{CFS}=\Delta \tau-\mu^{\prime} \Delta \sigma_{n},
$$

where $\Delta \tau$ is the shear stress change, $\mu^{\prime}$ is the effective frictional coefficient, and $\Delta \sigma_{n}$ is the normal stress change. We set the effective frictional coefficient $\mu^{\prime}$ to be $0.4^{11,22,32,47,48}$. The fault dimension is assumed to follow an empirical relationship with the seismic moment ${ }^{49}$. The ambient compressional stress field is oriented in the $N 77^{\circ} \mathrm{E}$ direction, with a strength of 65 bars $^{6,7,11,22}$ (Fig. 1). In addition, we set the lithospheric Young's modulus to be $80 \mathrm{GPa}$ and the Poisson's ratio to be $0.25^{11,22,46,47}$. The Coulomb stress changes induced by the earthquakes are calculated for media with strike-slip faults in the optimal orientation or given orientation ${ }^{50}$.

\section{References}

1. Chough, S. K., Kwon, S.-T., Ree, J.-H. \& Choi, D.-K. Tectonic and sedimentary evolution of the Korean Peninsula: a review and new view. Earth Science Reviews 52, 175-235 (2000).

2. Hong, T.-K., Baag, C.-E., Choi, H. \& Sheen, D.-H. Regional seismic observations of the 9 October 2006 underground nuclear explosion in North Korea and the influence of crustal structure on regional phases. Journal of Geophysical Research 113, B03305, https://doi.org/10.1029/2007JB004950 (2008).

3. Hong, T.-K. \& Kang, T.-S. Pn travel-time tomography of the paleo-continental-collision and rifting zone around Korea and Japan. Bulletin of the Seismological Society of America 99, 416-421 (2009).

4. Jo, E. \& Hong, T.-K. Vp/Vs ratios in the upper crust of the southern Korean Peninsula and their correlations with seismic and geophysical properties. Journal of Asian Earth Sciences 66, 204-214 (2013).

5. Furumura, T., Hong, T.-K. \& Kennett, B. L. N. Lg wave propagation in the area around Japan: Observations and simulations. Progress in Earth and Planetary Science 1(10), https://doi.org/10.1186/2197-4284-1-10 (2014).

6. Lee, J., Hong, T.-K. \& Chang, C. Crustal stress field perturbations in the continental margin around the Korean Peninsula and Japanese islands. Tectonophysics 718, 140-149 (2017).

7. Choi, H., Hong, T.-K., He, X. \& Baag, C.-E. Seismic evidence for reverse activation of a paleo-rifting system in the East Sea (Sea of Japan). Tectonophysics 572-573, 123-133 (2012).

8. Lee, K. \& Yang, W.-S. Historical seismicity of Korea. Bulletin of the Seismological Society of America 96, 846-855 (2006).

9. Houng, S. E. \& Hong, T.-K. Probabilistic analysis of the Korean historical earthquake records. Bulletin of the Seismological Society of America 103, 2782-2796 (2013).

10. Yagi, Y. \& Fukahata, Y. Rupture process of the 2011 Tohoku-oki earthquake and absolute elastic strain release. Geophysical Research Letters 38, L19307, https://doi.org/10.1029/2011GL048701 (2011).

11. Hong, T.-K., Lee, J. \& Houng, S. E. Long-term evolution of intraplate seismicity in stress shadows after a megathrust. Physics of the Earth and Planetary Interiors 245, 59-70 (2015).

12. Hong, T.-K., Lee, J., Chi, D. \& Park, D. Seismic velocity changes in the backarc continental crust after the $2011 M_{w} 9.0$ Tohoku-Oki megathrust earthquake. Geophysical Research Letters 44, 10997-11003, https://doi.org/10.1002/2017GRL075447 (2017).

13. Kim, S.-K. \& Bae, T.-S. Analysis of crustal deformation on the Korea Peninsula after the 2011 Tohoku earthquake. Journal of the Korean Society of Surveying, Geodesy, Photogrammetry, and Cartography 30 (In Korean) 87-96 (2012).

14. Zhao, B. et al. Far field deformation analysis after the Mw9.0 Tohoku earthquake constrained by cGPS data. Journal of Seismology 16, 305-313 (2012).

15. Kim, D., Park, K. D., Ha, J., Sohn, D. H. \& Won, J. Geodetic analysis of post-seismic crustal deformations occurring in South Korea due to the Tohoku-Oki earthquake. KSCE Journal of Civil Engineering 20, 2885-2892 (2016a).

16. Brenguier, F. et al. Mapping pressurized volcanic fluids from induced crustal seismic velocity drops. Science 345, 80-82 (2014).

17. Nakata, N. \& Smoeder, R. Near-surface weakening in Japan after the 2011 Tohoku-Oki earthquake. Geophysical Research Letters 38, L17302, https://doi.org/10.1029/2011GL048800 (2011).

18. Minato, S., Tsuji, T., Ohmi, S. \& Matsuoka, T. Monitoring seismic velocity change caused by the 2011 Tohoku-oki earthquake using ambient noise records. Geophysical Research Letters 39, L09309, https://doi.org/10.1029/2012GL051405 (2012).

19. Nakahara, H. Auto correlation analysis of coda waves from local earthquakes for detecting temporal changes in shallow subsurface structures: the 2011 Tohoku-Oki, Japan earthquake. Pure and Applied Geophysics 172, 213-224 (2015).

20. Stein, R. S. The role of stress transfer in earthquake occurrence. Nature 402, 605-609 (1999).

21. Watts, A. B. \& Burov, E. B. Lithospheric strength and its relationship to the elastic and seismogenic layer thickness. Earth and Planetary Science Letters 213, 113-131 (2003).

22. Hong, T.-K. et al. The 12 September $2016 M_{L} 5.8$ mid-crustal earthquake in the Korean Peninsula and its seismic implications. Geophysical Research Letters 44, 3131-3138, https://doi.org/10.1002/2017GL072899 (2017).

23. Brodsky, E. E. \& van der Elst, N. J. The uses of dynamic earthquake triggering. Annual Review of Earth and Planetary Sciences 42, 317-339 (2014).

24. Scholz, C. H. On the stress dependence of the earthquake b value. Geophysical Research Letters 42, 1399-1402, https://doi. org/10.1002/2014GL062863 (2015).

25. Gardner, J. K. \& Knopoff, L. Is the sequence of earthquakes in Southern California, with aftershocks removed, Poissonian? Bulletin of the Seismological Society of America 64, 1363-1367 (1974).

26. Wang, Z. Seismic hazard assessment: issues and alternatives. Pure and Applied Geophysics 168, 11-25 (2011).

27. Gomberg, J., Blanpied, M. L. \& Beeler, N. M. Transient triggering of near and distant earthquakes. Bulletin of the Seismological Society of America 87, 294-309 (1997).

28. Hong, T.-K., Park, S. \& Houng, S. E. Seismotectonic properties and zonation of the far-eastern Eurasian plate around the Korean Peninsula. Pure and Applied Geophysics 173, 1175-1195 (2016). 
29. Park, S. \& Hong, T.-K. Regional seismic intensity anomalies in the Korean Peninsula and its implications for seismic-hazard potentials. Pure and Applied Geophysics 174, 2561-2579 (2017).

30. Nandan, S., Ouillon, G., Woessner, J., Sornette, D. \& Wiemer, S. Systematic assessment of the static stress triggering hypothesis using interearthquake time statistics. Journal of Geophysical Research 121, 1890-1909 (2016).

31. Toda, S. \& Stein, R. Toggling of seismicity by the 1997 Kagoshima earthquake couplet: A demonstration of timedependent stress transfer. Journal of Geophysical Research 108, 2567, https://doi.org/10.1029/2003JB002527 (2003).

32. Ma, K. F., Chan, C. H. \& Stein, R. S. Response of seismicity to Coulomb stress triggers and shadows of the $1999 M_{w}=7.6$ Chi-Chi, Taiwan, earthquake. Journal of Geophysical Research 110, B05S19, https://doi.org/10.1029/2004JB003389 (2005).

33. Hough, S. E., Seeber, L. \& Armbruster, J. G. Intraplate Triggered Earthquakes: Observations and Interpretation. Bulletin of the Seismological Society of America 93, 2212-2221 (2003).

34. Jiang, T., Peng, Z., Wang, W. \& Chen, Q.-F. Remotely triggered seismicity in continental China following the $2008 \mathrm{Mw} 7.9$ Wenchuan earthquake. Bulletin of the Seismological Society of America 100, 2574-2589 (2010).

35. Park, S. \& Hong, T.-K. Joint Determination of Event Epicenter and Magnitude from Seismic Intensities. Bulletin of the Seismological Society of America 106, 499-511 (2016).

36. Talwani, P. Intraplate Earthquakes, (Cambridge University Press, New York, p332 2014).

37. Marsan, D. \& Lengliné, O. Extending earthquakes' reach through cascading. Science 319, 1076-1079 (2008).

38. Zhuang, J., Ogata, Y. \& Vere-Jones, D. Analyzing earthquake clustering features by using stochastic reconstruction. Journal of Geophysical Research 109, B05301, https://doi.org/10.1029/2003JB002879 (2004).

39. Nandan, S., Ouillon, G., Wiemer, S. \& Sornette, D. Objective estimation of spatially variable parameters of epidemic type aftershock sequence model: Application to California. Journal of Geophysical Research: Solid Earth 122, 5118-5143, https://doi.org/10.1002/ 2016JB013266 (2017).

40. Dreger, D. S. \& Helmberger, D. V. Broadband modeling of local earthquakes. Bulletin of the Seismological Society of America 80, $1162-1179$ (1990).

41. Kennett, B. L. N., Engdahl, E. R. \& Buland, R. Constraints on seismic velocities in the Earth from traveltimes. Geophysical Journal International 122, 108-124 (1995).

42. Saikia, C. K. Modified frequency-wavenumber algorithm for regional seismograms using Filon's quadrature: modelling of Lg waves in eastern North America. Geophysical Journal International 118, 142-158 (1994).

43. Kim, W., Hong, T.-K. \& Kang, T.-S. Hypocentral parameter inversion for regions with poorly known velocity structures. Tectonophysics 627, 182-192 (2014).

44. Kim, W., Hong, T.-K., Lee, J. \& Taira, T. A. Seismicity and fault geometry of the San Andreas fault around Parkfield, California and their implications. Tectonophysics 677, 34-44 (2016b).

45. Chang, S.-J. \& Baag, C.-E. Crustal structure in Southern Korea from joint analysis of regional broadband waveforms and travel times. Bulletin of the Seismological Society of America 96, 856-870 (2006).

46. King, G. C. P., Stein, R. S. \& Lin, J. Static stress changes and the triggering of earthquakes. Bulletin of the Seismological Society of America 84, 935-953 (1994)

47. Toda, S., Stein, R. S., Richards-Dinger, K. \& Bozkurt, S. B. Forecasting the evolution of seismicity in southern California: Animations built on earthquake stress transfer. Journal of Geophysical Research 110, B05S16, https://doi.org/10.1029/2004JB003415 (2005).

48. Nalbant, S. S., Hubert, A. \& King, G. C. P. Stress coupling between earthquakes in northwest Turkey and the north Aegean Sea. Journal of Geophysical Research 103, 24469-24486 (1998).

49. Wells, D. L. \& Coppersmith, K. J. New empirical relationships among magnitude, rupture length, rupture width, rupture area, and surface displacement. Bulletin of the seismological Society of America 84, 974-1002 (1994).

50. Lee, J. \& Hong, T.-K. Dynamic lithospheric response to megathrust and precursory seismicity features of megathrust. Physics of the Earth and Planetary Interiors 234, 35-45 (2014).

\section{Acknowledgements}

The analysis results from the processed data are presented in the supporting information. The seismicity and station information are available from the Japan Meteorological Agency (JMA, www.jma.go.jp/jma/indexe.html). This work was supported by grant 2017-MPSS31-007 from the Supporting Technology Development Program for Disaster Management funded by the Korean Ministry of Interior and Safety (MOIS) and by grant NRF2017R1A6A1A07015374 from the Basic Science Research Program through the National Research Foundation of Korea (NRF) funded by the Ministry of Education.

\section{Author Contributions}

T.K.H. wrote the paper, guided all the analyses, and interpreted the results. J.L., S.P. and W.K. analyzed the waveform records. The authors discussed the results and provided comments on the manuscript.

\section{Additional Information}

Supplementary information accompanies this paper at https://doi.org/10.1038/s41598-018-31600-5.

Competing Interests: The authors declare no competing interests.

Publisher's note: Springer Nature remains neutral with regard to jurisdictional claims in published maps and institutional affiliations.

Open Access This article is licensed under a Creative Commons Attribution 4.0 International License, which permits use, sharing, adaptation, distribution and reproduction in any medium or format, as long as you give appropriate credit to the original author(s) and the source, provide a link to the Creative Commons license, and indicate if changes were made. The images or other third party material in this article are included in the article's Creative Commons license, unless indicated otherwise in a credit line to the material. If material is not included in the article's Creative Commons license and your intended use is not permitted by statutory regulation or exceeds the permitted use, you will need to obtain permission directly from the copyright holder. To view a copy of this license, visit http://creativecommons.org/licenses/by/4.0/.

(c) The Author(s) 2018 